\title{
Hematopoietic stem cell transplantation
}

This article was published in the following Dove Press journal:

Stem Cells and Cloning:Advances and Applications

25 August 2010

Number of times this article has been viewed

\section{Eleftheria Hatzimichael' Mark Tuthill ${ }^{2}$ \\ 'Department of Haematology, Medical School of loannina, University of loannina, loannina, Greece; ${ }^{2}$ Department of Medical Oncology, Hammersmith Hospital, Imperial College National Health Service Trust, London, UK}

\begin{abstract}
More than 25,000 hematopoietic stem cell transplantations (HSCTs) are performed each year for the treatment of lymphoma, leukemia, immune-deficiency illnesses, congenital metabolic defects, hemoglobinopathies, and myelodysplastic and myeloproliferative syndromes. Before transplantation, patients receive intensive myeloablative chemoradiotherapy followed by stem cell "rescue." Autologous HSCT is performed using the patient's own hematopoietic stem cells, which are harvested before transplantation and reinfused after myeloablation. Allogeneic HSCT uses human leukocyte antigen (HLA)-matched stem cells derived from a donor. Survival after allogeneic transplantation depends on donor-recipient matching, the graft-versus-host response, and the development of a graft versus leukemia effect. This article reviews the biology of stem cells, clinical efficacy of HSCT, transplantation procedures, and potential complications.
\end{abstract}

Keywords: hematopoietic stem cell transplantation, complications

\section{Stem cell function and differentiation}

Stem cells are found throughout the body and can be defined as a population of undifferentiated cells capable of indefinite self-renewal and generation of a functional progeny of highly specialized cells. Stem cells have different proliferative properties and functions depending on their physical location or tissue compartment. Hematopoietic stem cells (HSCs) are characterized by the ability to self-renew and differentiate into all mature blood lineages. ${ }^{1,2}$ Hematopoiesis is a continuous developmental process in which HSCs make specific cell fate decisions, producing the various blood lineages. ${ }^{3}$

The generation and maintenance of appropriate numbers and types of mature cells require a complex regulatory network that is incompletely understood. The differentiation and proliferation of hematopoietic cells are regulated by stromal interactions with soluble and cell-bound cytokines. ${ }^{4}$ The most primitive HSCs express the cell surface antigen CD34 and receptors for the early-acting hemopoietic growth factors: kinase domain receptor (KDR [flk-1]), vascular endothelial growth factor, and the positive hemopoietic development regulators, c-kit and flt-3, which can be used for ex vivo expansion of HSCs. ${ }^{5}$

HSCs for transplantation can be collected from bone marrow (BM) or peripheral blood. Hematopoietic reconstitution after BM ablation depends on the migration and "homing" of intravenously transplanted stem cells to the hematopoietic microenvironment in the BM niches of the recipient ${ }^{6}$ (Figure 1). HSC "homing" is a multistep process involving sequential activation of adhesion molecules. ${ }^{7}$ The chemokine
Correspondence: Mark Tuthill Department of Medical Oncology, Hammersmith Hospital, Imperial College National Health Service Trust, Ducane Rd, London, WI2 OHS, UK Tel +44208383 1000 Fax +442076039679

Email marktuthill@doctors.org.uk 
stromal cell-derived factor-1 (SDF-1) was the first identified chemoattractant for monocytes, lymphocytes, and CD34 ${ }^{+}$ cell homing. ${ }^{8,9}$

CXCR $4^{+}$progenitors are activated by SDF-1 and vascular ligands, such as intercellular adhesion molecule-1 and vascular cellular adhesion molecule-1, which facilitate firm adhesion to endothelial cells. Circulating transplanted cells interact with BM vascular endothelial cells "rolling" on constitutively expressed endothelial (E) and platelet (P) selectins. Cells expressing insufficient levels of CXCR4 detach and return to the bloodstream. ${ }^{10}$

In humans, $\mathrm{SDF}-1$ arrests $\mathrm{CXCR} 4^{+}$stem cells, facilitating extravasation through extracellular BM matrix barriers into the hematopoietic compartments. SDF-1 and macrophage inflammatory protein- 1 activate the binding of $\mathrm{CD} 34^{+}$cells to the extracellular matrix protein fibronectin via very late activation antigen-5 (VLA)-5 and VLA-4 integrin receptors. ${ }^{11}$ Finally, migrating stem cells reach "stem cell niches" where they interact with supporting cells, adhesion molecules, SDF-1, and growth factors.

The transplanted hematopoietic progenitors are depleted by the homing process and only form a small part of the transplant recipient's stem cell pool. The true stem cells divide slowly, ${ }^{12,13}$ avoiding exhaustion by limiting expansion and reverting to a dormant state when mature compartments are fully reconstituted. Despite adverse conditions in the host $\mathrm{BM}$ niches, the infused HSCs generate sufficient progenitors to repopulate the host hematopoietic system with mature cells. Granulocyte-macrophage colony-forming units return to normal levels within 2 years of transplantation.

\section{Rationale for hematopoietic stem cell transplantation - how transplantation works}

The indications for hematopoietic stem cell transplantation (HSCT) depend on the patient's medical condition, the therapeutic objectives, and the availability and source of stem cells (Table 1). In 2006, the Center for International Blood and Marrow Transplant Research (IBMTR) collected data from more than 400 worldwide transplant centers and found that hematological malignancies (and premalignant conditions) are the most common indications for allogeneic HSCT. Acute myeloid leukemia (AML) accounts for $33 \%$ of allogeneic HSCTs, acute lymphoblastic leukemia $16 \%$, chronic myeloid leukemia $6 \%$, other leukemias and preleukemias 18\%, Hodgkin lymphoma (HL) and nonHodgkin lymphoma (NHL) 12\%, and multiple myeloma (MM) 3\%.
Table I Disorders treated by hematopoietic stem cell transplantation (HSCT)

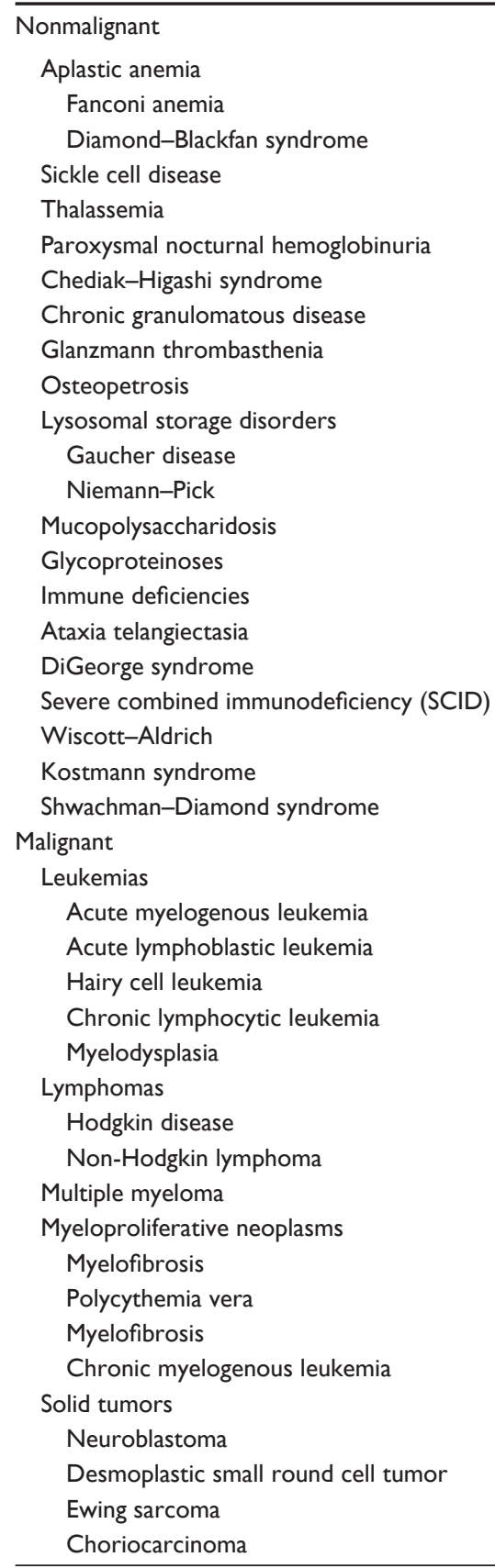

The use of allogeneic HSCT for hematological malignancies in the 1980s and early 1990s was largely restricted to younger patients ( $\leq 45$ years old) with a human leukocyte antigen (HLA)-identical sibling donor. Less-intensive conditioning regimens and improved graftversus-host disease (GvHD) prophylaxis and supportive care have increased the use of allogeneic HSCT in older patients. In 1987-1992, only 4\% of allogeneic HSCT recipients were older than 50 years. In 2006, 33\% of allogeneic HSCT 
recipients were older than 50 years, and $11 \%$ were older than 60 years.

The application of HSCT in patients without HLAidentical siblings has been facilitated by the establishment of large unrelated donor registries, such as the Anthony Nolan Trust in the United Kingdom. Between 1987 and 1992, less than $10 \%$ of HSCTs for hematological malignancies used unrelated donors; in 2006, this figure was greater than $40 \%$.

HSCT allows the use of higher doses of chemotherapy that would otherwise be fatal in a conventional setting. Autologous or allogeneic HSCs are used as a "rescue" after the induction of life-threatening myelosuppression. Autologous HSCT is most effective when there is direct correlation between chemotherapy dose and tumor response and when the doselimiting treatment toxicity is myelosuppression. In allogeneic HSCT, the conditioning regimen eradicates malignant cells, ineffective hematopoietic cells, and host immune cells, which may reject the donor cells. Although HSCT was originally regarded as a way of rescuing patients from therapy-induced marrow aplasia, it is now accepted that alloreactive donor cells confer a substantial graft-versus-tumor (GvT) effect, which contributes to cancer eradication.
HSCT is also an established treatment for congenital or acquired BM failure, immunodeficiency states, and autoimmunity. ${ }^{14}$ In these cases, the GvT effect is not desired, and prevention of GvHD is a priority. HSCs can also act as "therapeutic vehicles" to replace defective or missing enzymes, such as adenosine deaminase, or to introduce genes that mediate antitumor activity (eg, interleukin-2). Infused HSCs can be genetically modified to maximize the GvT effect and to include "suicide genes" for donor cell elimination in the event of GvHD. ${ }^{15,16}$ Lymphohematopoietic cells can be used in conjunction with solid organ transplants, as microchimerism facilitates the establishment of transplanted organ tolerance. ${ }^{17}$

In allogeneic HSCT, hematopoietic stem and progenitor cells, from donor marrow or other sources, are intravenously infused. The stem cells "home" to the recipient's hematopoietic microenvironment and engraft in the BM niches. ${ }^{18}$ Under optimal circumstances, the recipient's immune system tolerates donor cell engraftment without nonengraftment or late graft failure. Donor immune effector cells interact with the recipient's immune cells and sustainably engraft without inducing fatal GvHD. Eventually,

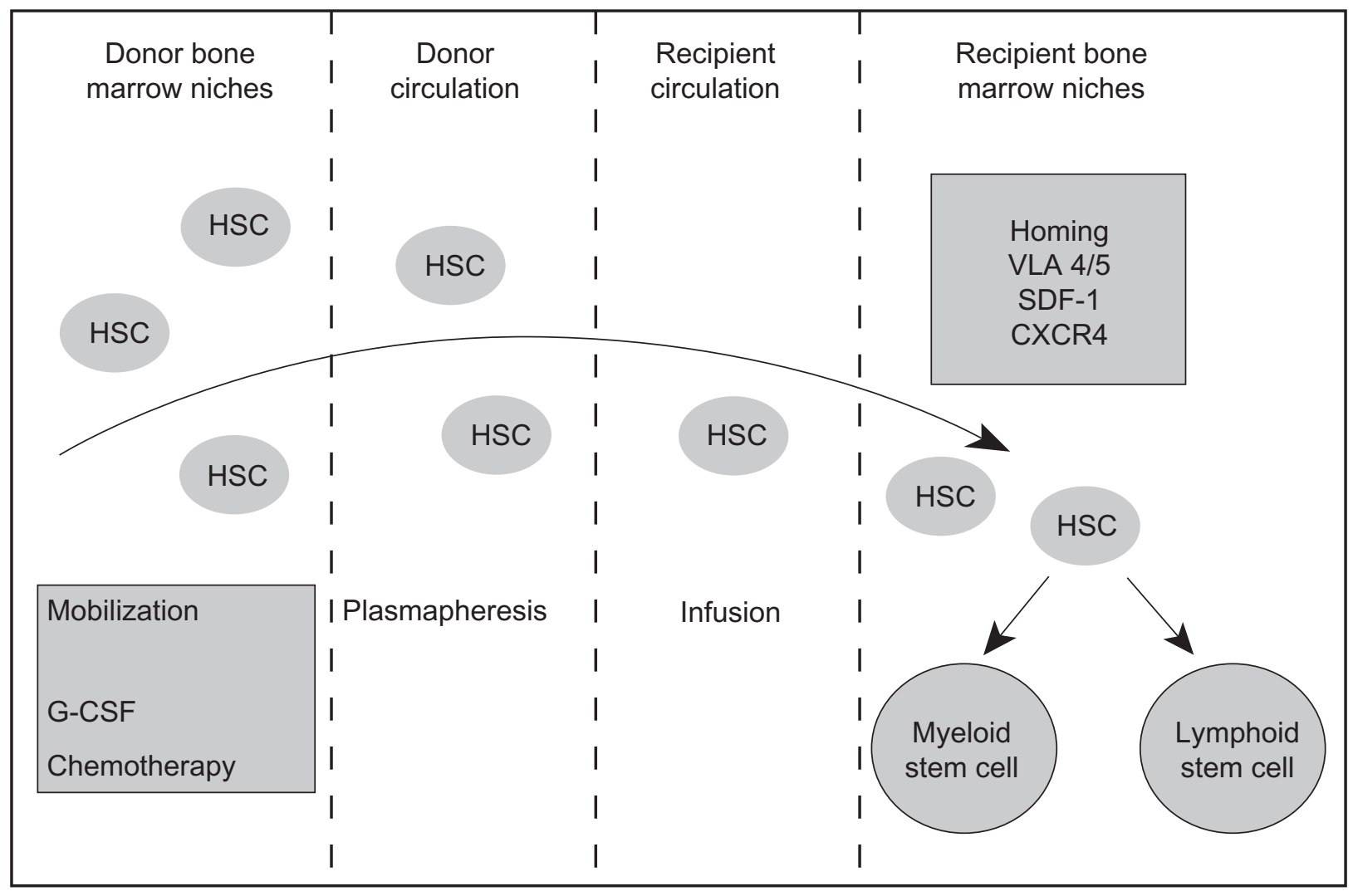

Figure I The mobilization and homing of hematopoietic stem cells (HSCs) to the bone marrow niches of the transplant recipient. Abbreviations: VLA-4/5, very late activation antigen; SDF-I, stromal cell-derived factor-I; G-CSF, granulocyte colony-stimulating factor. 
a stable chimeric state predominates, with reconstitution of functional B lymphocytes, T lymphocytes, and natural killer cells, along with a sustained GvT effect. ${ }^{19}$

Observations by Kolb et al, ${ }^{20}$ that an infusion of lymphocytes from the original donor could treat relapses of chronic myelogenous leukemia after allogeneic transplantation, provided compelling evidence of an immunotherapeutic GvT effect. This has lead to the development of nonmyeloablative conditioning regimes, which gradually replace the host lymphohematopoietic compartment (normal and malignant cells) by donor-derived cells.

\section{Selection of stem cell source}

The HSC categories are autologous, syngeneic, and allogeneic. Selection of HSC source depends on the donor availability and transplantation indication. Extensive prior cytotoxic therapy and heavy malignant involvement of marrow or peripheral blood often precludes the use of autologous HSCs. HLA-matched sibling donors are preferred for allogeneic transplants; however, less than $30 \%$ of patients have a suitable donor. $^{21}$ Patients without a sibling donor have a 30\%-40\% chance of finding a phenotypically HLA-matched unrelated donor through volunteer registries. ${ }^{22}$ The development of cord blood HSCs has increased the chance of finding allogeneic donors for pediatric and adult patients. ${ }^{23-25}$

Autologous, syngeneic, or allogeneic HSCs support hematopoietic recovery after myeloablative chemoradiotherapy for malignant hematological and nonhematological diseases. Syngeneic or allogeneic HSCs are used for acquired disorders of marrow function (eg, aplastic anemia) and correction of congenital hematopoietic or immunological defects (eg, thalassemia and severe combined immunodeficiency syndrome). ${ }^{26,27}$

\section{How stem cells are generated for HSCT}

HSC products for autologous or allogeneic transplantation are available from BM, peripheral blood, or umbilical cord blood (UCB).

\section{Bone marrow}

$\mathrm{BM}$ is harvested from the posterior iliac crests under epidural or general anesthesia. The anterior iliac crest or sternum can be used if larger quantities of marrow are required. The BM is collected with heparinized syringes and large-bore needles and is stored in culture medium. The marrow can be infused immediately after harvesting but can be stored at $4{ }^{\circ} \mathrm{C}$ for 24 hours without loss of stem cell viability, allowing national and international transfers of HSCs between transplant programs.

The cell dose required for stable long-term engraftment is not clearly defined. A nucleated cell dose of $2 \times 10^{8} / \mathrm{kg}$ is generally considered adequate, although cell doses of $1 \times 10^{8} / \mathrm{kg}$ can be used. ${ }^{28}$ This requires between 700 and 1,500 $\mathrm{mL}$ of BM from an adult donor. National Marrow Donor Program guidelines limit BM removal to $15 \mathrm{~mL} / \mathrm{kg}$ of donor weight. As only a small percentage of total body $\mathrm{BM}$ is removed, peripheral blood leukocyte counts are not affected.

After harvesting, the marrow is filtered to remove small particles or clots before intravenous transfusion into the recipient. Red blood cells and plasma can be depleted if the recipient has high anti-A or anti-B antibody titers and major or minor $\mathrm{ABO}$ mismatches. ${ }^{29}$ In the event of a major $\mathrm{ABO}$ mismatch, plasmapheresis of the recipient can reduce high anti-A or anti-B titers, so that red blood cell depletion of marrow is not required.

In an analysis of marrow harvests from 1,549 donors, the harvested median total nucleated cell count was $2.5 \times 10^{8} / \mathrm{kg}$ recipient weight (range, $0.3-12.0) .{ }^{30}$ The incidence of lifethreatening complications from marrow harvesting is around $0.27 \%-0.4 \%$ and predominantly relates to anesthetic risk. ${ }^{31}$

\section{Peripheral blood stem cells}

Peripheral blood stem cells (PBSCs) are widely used for allogeneic HSCT and have virtually replaced BM as the HSCT component for autologous HSCs. PBSCs engraft more quickly than BM-derived stem cells. After PBSC transplantation, the median time to an absolute neutrophil count greater than $500 / \mu \mathrm{L}$ and platelet transfusion independence is typically around 11-14 days. ${ }^{32,33}$

Improvements in engraftment kinetics reduce autologous transplantation costs. ${ }^{34,35}$ Peripheral blood HSCs are found in low numbers, requiring multiple aphereses for adequate collection. The number of leukaphereses may be reduced to one or two sessions by mobilization of HSCs to the peripheral blood with granulocyte colony-stimulating factor (G-CSF) at a rate $6 \mu \mathrm{g} / \mathrm{kg} /$ day with or without chemotherapy. ${ }^{36}$

After chemotherapy, patients are leukapheresed when the total white blood cell count has recovered to $1,000 / \mu \mathrm{L}$ or when the $\mathrm{CD} 34^{+}$cell count in the peripheral blood is at least $>10 / \mu \mathrm{L}$. Leukapheresis can be performed as early as day 4 using a continuous blood flow separation technique. For normal allogeneic donors or patients who do not require chemotherapy, mobilization is with G-CSF alone $(5-16 \mu \mathrm{g} / \mathrm{kg})$ by daily subcutaneous injections for 5-8 days. ${ }^{37-39}$ 
The incidences of moderate to severe adverse effects of G-CSF administration are as follows: bone pains, $84 \%$ of patients; headache, $54 \%$ of patients; fatigue, $31 \%$ of patients; and nausea, $13 \%$ of patients. ${ }^{40}$ There are no absolute contraindications to the stimulation of healthy donors with G-CSF, but rare occurrences of nontraumatic splenic rupture do occur. ${ }^{41-44}$

Pheresed products may be cryopreserved in 5\% dimethylsulfoxide (DMSO) for frozen storage until transplantation. Sustained and faster hematopoietic recovery of neutrophil and platelet counts occurs with increasing $\mathrm{CD} 34^{+}$cell numbers in the hematopoietic cell graft (up to $5 \times 10^{6} / \mathrm{kg}$ ). ${ }^{36}$ For complete autologous recovery, some investigators consider $2.5 \times 10^{6} / \mathrm{kg}$ of recipient weight to be the minimum dose of peripheral blood CD34 ${ }^{+}$cells.

Since the cell dose used in the autologous transplant setting yields consistent and prompt engraftment, allogeneic HSCs can be routinely collected from the peripheral blood. This avoids general anesthesia and other common complications of marrow harvesting, such as back pain, fatigue, and bleeding from the harvest site. If peripheral veins are inadequate, a large-bore vascular access double-lumen catheter may be required.

The disadvantages of PBSC components compared with $\mathrm{BM}$ or UCB for autologous or allogeneic transplantation include multiday collections (especially for autologous transplantation), inability to collect adequate components from all patients and donors, and a slightly higher risk of difficult-to-treat GvHD. ${ }^{45,46}$

\section{Umbilical cord blood}

For allogeneic HSCT, lack of a suitably matched HLA donor, particularly for ethnic minorities, limits the chance of receiving a transplant. One solution to the shortage of donors is the development of cord blood banks, such as the recently opened Anthony Nolan Cord Blood Bank at Nottingham Trent University in the United Kingdom, which will bank stem cells from 50,000 cord bloods by 2013 .

Cord blood transplantation (CBT) has important advantages including easy and safe procurement, easy availability, reduced potential for viral transmission, and relatively immature immune cells, which reduce the incidence of GvHD. ${ }^{47}$ However, CBTs contain fewer cells than other HSCT cell sources which delays hematological recovery, increases infection risk, and early posttransplant period mortality. ${ }^{48}$

CBT has found an important niche for patients without a suitable related or unrelated volunteer. The donor cells are relatively immunologically naive, which allows multiple-antigen mismatches. A match of 3-4 of the 6 HLA-A, HLA-B, and HLA-DRB1 antigens is sufficient for CBT and reduces the risk of GvHD.

Cord blood has a higher enrichment of stem cells than BM or peripheral blood. ${ }^{48,49}$ Around $40-70 \mathrm{~mL}$ of fetal cord blood is collected immediately after the cord is clamped and cut. The placenta is separated, and the UCB cells are collected into a sterile donor blood collection set. The placenta and umbilical cord are suspended on a frame, and blood is drained by "standard gravity phlebotomy" into citrate phosphate dextrose (CPD) anticoagulant. ${ }^{50}$ The units are cryopreserved and stored in cord blood banks. If the cord is appropriately clamped, the collection poses no donor risks.

Novel culture strategies that increase $\mathrm{CD} 34^{+}$cord blood progenitor numbers are in development. A recent study of a notch ligand and an ex vivo culture system produced a 100-fold expansion of $\mathrm{CD} 34^{+}$stem cells, and results from a phase 1 study showed a reduction in neutrophil engraftment times. $^{51}$

A meta-analysis comparing unrelated donor CBT and unrelated donor $\mathrm{BM}$ transplantation in adult and pediatric patients found that the risk of chronic GvHD (cGvHD) was significantly lower after allogeneic cord blood HSCT (relative risk $[R R]=0.41 ; 95 \%$ confidence interval $[\mathrm{CI}], 0.25-0.68)$. In adults, BM-derived HSCT was associated with a lower relapse rate and improved overall survival (OS). ${ }^{52}$

\section{The safety and efficacy of bone marrow transplantation}

HSCT is the only potentially curative treatment for patients with chemotherapy-resistant hematological malignancies, which are usually fatal in the absence of treatment. HSCT is associated with both significantly early $(<100$ days after transplant) and late ( $>100$ days after transplant) morbidity and mortality. Around $4 \%$ of patients will die within 100 days of autologous or allogeneic HSCT..$^{53}$ Outcomes for non-relapse related mortality (NRM) can be as high as $46 \% .^{54}$

HSCT mortality is affected by the comorbidities, disease characteristics, HLA matching, GvHD, the GvT effect, and posttransplantation recurrence. Relapse-related mortality reflects tumor biology and NRM complications arising from HSCT procedures and patient comorbidities. Improved outcomes are due to improvements in tissue typing, prophylaxis against viral and fungal infection, immunosuppressive drugs, and supportive care.

The development of reduced intensity conditioning (RIC) regimes has allowed HSCT in older patients, typically defined as those $\geq 50$ years, although older patients receiving RIC 
have a higher relapse rate. ${ }^{55}$ Outcomes for children with severe aplastic anemia are excellent with 5-year survival rates of around $90 \%$ for unrelated sibling transplants and $100 \%$ for matched sibling donor transplants. ${ }^{56}$

\section{The hematopoietic cell transplantation comorbidity index}

The hematopoietic cell transplantation comorbidity index (HCT-CI) was developed by investigators at the Fred Hutchinson Cancer Research Center (Seattle, Washington, USA) to allow the risk assessment of patients undergoing transplantation..$^{57,58}$ The investigators collected retrospective data from 1,055 patients undergoing nonablative $(\mathrm{n}=294)$ and ablative $(\mathrm{n}=761)$ conditioning prior to stem cell transplantation. The median age of the group was 45 years old and, most of the diagnoses (66\%) were myeloid malignancies. ${ }^{57}$

The HCT-CI uses a comorbidity-based scoring system, which adjusts for age, disease risk, and conditioning regimen, to predict 2-year NRM after transplantation. Patients are classified into three risk groups: low risk (NRM, 14\% at 2 years); intermediate risk (NRM, 21\% at 2 years); and high risk (NRM, $41 \%$ at 2 years). ${ }^{57}$ The HCT-CI successfully predicted NRM, OS, and progression-free survival in a cohort of 203 patients with NHL, HL, MM, ${ }^{59}$ and in patients with myelodysplastic syndromes or AML receiving alemtuzumab-based RIC HSCT. ${ }^{55}$

Although HCT-CI is a strong predictor of outcome, other investigators have questioned the ability of the HCT-CI to predict NRM and OS. ${ }^{60}$ Defor et $\mathrm{al}^{60}$ proposed a modified comorbidity index (MCI), which was developed using a pure multiplicative model in a cohort of 444 adult allogeneic HCT recipients. The MCI had a higher discriminating and predictive power for OS and NRM compared with the HCT-CI. Further validations of the HCT-CI and MCI in larger HSCT cohorts are required.

\section{Complications of HSCT}

The high chemotherapy doses used in HSCT cause significant drug toxicities and complications from prolonged immunodeficiency and require an extended recovery process. Recognition of risk factors for complications allows the design of risk-specific supportive-care regimens that reduce the incidence of transplantation morbidity and mortality. HCT-related complications are broadly classified into infections, early noninfectious complications (within 3 months of HSCT), late noninfectious complications (after 3 months of HSCT), and GvHD.

\section{Infection after HCT}

Infection is an important cause of morbidity and mortality after HSCT. Engraftment after autologous HSCT occurs within 7-14 days and from 14 to 28 days after allogeneic HSCT. The risk of infection is related to the time period after transplantation, which can be defined as pre-engraftment, less than 3 weeks; immediate postengraftment, 3 weeks to 3 months; and late postengraftment, more than 3 months. Allogeneic recipients are at risk of infection throughout all periods, but autologous transplant recipients are only at significant risk during the pre-engraftment and immediate postengraftment periods. The risk factors for infection during the pre-engraftment phase are disruption of mucocutaneous barriers, indwelling venous catheters, neutropenia, and organ dysfunction.

Total T cell $\left(\mathrm{CD}^{+}\right)$or CD4 cell levels can be used as a surrogate marker for T-cell immunity, although no definitive biomarkers exist for immune reconstitution that predict infection risk and need for antimicrobial prophylaxis. Consequently, patients need careful monitoring and early intervention for signs or symptoms of infection. Most centers continue antimicrobial prophylaxis until after the initial posttransplant period and 3-6 months after cessation of immunosuppression.

HSCT survivors may be offered vaccinations at 12 months posttransplantation. Current guidelines for the management of infections in HCT recipients from the Centers for Disease Control and Prevention, The Infectious Disease Society of America, and The American Society of Blood and Marrow Transplantation can be found at www.cdc.gov.

In the initial posttransplant period, bacterial infections occur in up to $30 \%$ of transplant recipients, commonly arising from normal skin flora (coagulase-negative Staphylococcus) and the oropharynx and gastrointestinal tract (Streptococcus viridans, Enterococcus species, and enteric gram-negative bacilli). Other serious gram negative infections include Pseudomonas aeruginosa, Enterobacteriaceae, and Stenotrophomonas maltophilia. The commonest cause of infectious diarrhea is Clostridium difficile. Listeria monocytogenes may cause septicemia and meningitis, and patients are at risk of unusual nosocomially acquired infections, such as legionella. ${ }^{61}$

Infection with Aspergillus species and fungi is common after HCT. Risk factors for invasive candidiasis include prolonged severe neutropenia, use of broad-spectrum antibiotics, severe organ dysfunction, mucocutaneous damage, and yeast colonization with Candida species. The introduction of routine antifungal prophylaxis with triazole antimicrobials, 
especially fluconazole, reduces the morbidity and mortality of invasive candidiasis. However, the incidence of infections from triazole-resistant Candida species, such as C. krusei and C. glabrata has increased. ${ }^{62}$

Invasive aspergillosis occurs in around 5\% and 30\% of patients after autologous and allogeneic HCT, respectively. Risk factors for aspergillosis infection include older age, GvHD, corticosteroid therapy, graft failure, a diagnosis other than chronic myelogenous leukemia, and advanced cancer at transplantation. Pneumocystis carinii (P. jirovecii) pneumonia (PCP) tends to occur at around 9 weeks after HCT, but routine prophylaxis limits the incidence to around 1\%-2\% of all transplant-related pneumonia.

In the immediate postengraftment period, the risk factors for infection are mucocutaneous damage, cellular immune dysfunction, immunomodulating viral infections, such as cytomegalovirus (CMV) and human herpes 6 viruses, hyposplenism, and decreased opsonization and reticuloendothelial function. Severe immune dysfunction is enhanced and prolonged by acute and chronic GvHD, corticosteroids, and immunosuppressive treatments. ${ }^{63}$

Autologous HSCs engraft and reconstitute immunity quicker than allogeneic HSCs, reducing infection incidences. After allogeneic HSCT, immune reconstitution can take up to 2 years. Patients requiring long-term immunosuppression for cGvHD are particularly susceptible to infection by encapsulated bacteria (Streptococcus pneumonia, Neisseria meningitides, and Haemophilus influenzae), fungi (Aspergillus species, Candida species, and P. jirovecii), and viruses (CMV and varicella zoster virus). Other factors that prolong immune deficiencies include donor - recipient HLA disparity, graft manipulation with depletion of T cells, use of an unrelated donor, and possibly cord blood stem cells.

Primary viral infection with Epstein-Barr virus (EBV) or reactivation of latent viral infections with CMV or human herpes viruses is a common cause of morbidity and mortality after HSCT. Patients should be educated about reducing their risk of acquiring new viral infections, especially for infections, such as EBV and varicella zoster virus.

The risk of herpes viral infection is predominantly confined to seropositive patients, as almost all herpes infections occur due to viral reactivation rather than new primary infection. Reactivation rates are around $70 \%$ and are similar after autologous or allogeneic transplantation. The median time onset of herpes simplex virus disease is $2-3$ weeks, and around 100 days for CMV.

CMV infection is a common cause of morbidity and mortality after HSCT. Approximately $50 \%-85 \%$ of the general population are infected with CMV, which is transmitted by saliva, sexual contact, and blood products. After allogeneic HSCT, around $30 \%$ of patients will experience reactivation of latent CMV infection, which usually occurs within the late posttransplant period and is associated with a $46 \%$ mortality. ${ }^{64}$

The immune response against CMV is predominantly mediated by the cellular immune system. After the initial infection and immune response, the virus establishes lifelong latency. Primary CMV infection is usually asymptomatic in immunocompetant individuals, but reactivation or primary infection in immunocompromised patients can cause severe disease. Reactivation occurs in allogeneic transplantation when a CMV-negative recipient receives an allograft from a CMV-positive donor, or after depletion of CMV specific $\mathrm{T}$ cells.

CMV infection or reactivation after HSCT can cause pneumonitis, retinitis, hepatitis, colitis, and BM suppression. Risk factors for CMV infection include CMV viremia, the presence of GvHD, prolonged and persistent neutropenia, and the receipt of a CMV-positive graft. Patients can be monitored serologically for early signs of relapse by measuring phosphoprotein 65 (pp65) antigenemia, which is an abundant CMV viral matrix protein and an immunodominant $\mathrm{CMV}$ antigen. Quantitative plasma polymerase chain reactions for CMV DNA may be useful during periods of severe neutropenia when leukocyte numbers are insufficient for CMV pp65 antigenemia testing.

The risk of CMV infection can be reduced by matching CMV-positive donors to CMV-positive recipients and CMVnegative donors to $\mathrm{CMV}$-negative recipients. Early treatment of CMV is preferable to prophylaxis, as antiviral drugs are toxic, difficult to administer, and of limited efficacy. ${ }^{65}$ The antiviral drug ganciclovir is immunosuppressive, causes neutropenia, and delays recovery of CMV-specific lymphocytes. ${ }^{66}$ The prophylactic administration of immunoglobulins to high risk patients does not reduce the risk of CMV infection. ${ }^{67}$

There has been extensive research on vaccination strategies to prevent CMV infections in patients receiving HSCT and solid organ transplants, as well as neonatal CMV infection. ${ }^{6}$ Progress toward developing an effective CMV vaccination has been slow, in part because of the laborious task of discovering CMV vaccine epitopes ${ }^{69}$ and the fact that new infections occur with different viral strains. The viral coat phosphoprotein pp65 is the major immunodominant CMV antigen and a candidate for a peptide-based CMV vaccine. ${ }^{69} \mathrm{~A}$ recent placebo-controlled Phase II clinical trial of a CMV glycoprotein vaccine was terminated early 
after showing an encouraging efficacy of around $50 \% .^{70}$ A Phase III study has been initiated.

CMV infection and other transplant-related diseases, such as EBV-related lymphoproliferative disorders, can be treated and prevented by adoptive cellular transfer therapy. The HSCT creates a unique immunological environment, with the conditioning creating a "vacated space" within the $\mathrm{BM}$, allowing rapid expansion of adoptively transferred cells. Results from clinical trials have been promising, although technical issues, such as finding suitable donors and the generation of antigen-specific $\mathrm{T}$ cells from patients or donors, has prevented widespread adoption. ${ }^{68}$

Despite apparent immunological recovery, many HSCT recipients remain immunocompromised beyond the initial 2 years after transplantation, especially those with cGvHD, where infection remains the most important cause of morbidity and mortality. Research and novel therapies are needed to allow quicker immune reconstitution protection against infectious pathogens, to identify reliable surrogate markers of immunological recovery and to safely augment the GvT response.

\section{Graft-versus-host disease}

GvHD can be classified into acute GvHD (aGvHD), which occurs within 100 days of transplantation, and cGvHD, which occurs after 100 days of transplantation. This distinction is arbitrary, as aGvHD can present at around 3 months posttransplant after RIC, and signs of cGvHD occur within a 100 days of transplant. As aGvHD and cGvHD share common features, the recent National Institutes of Health (NIH) Consensus Conference proposed definitions of aGvHD or cGvHD, each with two subcategories, using the specificity of signs and symptoms rather than time of onset $^{71}$ (Table 2).

\section{Acute GvHD}

The overall incidence of clinically significant (grade II-IV) aGvHD is around $40 \%$, but varies from $10 \%$ to $80 \%$ according

Table 2 The definitions of acute and chronic GvHD

\begin{tabular}{|c|c|c|c|}
\hline Category & $\begin{array}{l}\text { Manifestation } \\
\text { time }\end{array}$ & $\begin{array}{l}\text { aGvHD } \\
\text { features }\end{array}$ & $\begin{array}{l}\text { cGvHD } \\
\text { features }\end{array}$ \\
\hline \multicolumn{4}{|l|}{ aGvHD } \\
\hline Classic & $\leq 100 d$ & Yes & No \\
\hline $\begin{array}{l}\text { Persistent, recurrent, } \\
\text { late onset }\end{array}$ & $>100 d$ & Yes & No \\
\hline \multicolumn{4}{|l|}{ cGvHD } \\
\hline Classic & No time limit & No & Yes \\
\hline Overlap syndrome & No time limit & Yes & Yes \\
\hline
\end{tabular}

Abbreviations: GvHD, graft-versus-host disease; aGvHD, acute GvHD; cGvHD, chronic GrHD. to number of risk factors. Risk factors for aGvHD include HLA disparity (related/unrelated), donor and recipient gender disparity, alloimunization of the donor (eg, multiparous females), increasing age of host, graft type (cord blood has a lower rate, and PBSCs have a higher rate when compared with BM-derived grafts), donor and host CMV status, and conditioning regimen. ${ }^{72,73}$ Even if fully matched, some HLA alleles are associated with a greater (ie, HLA-A10 and HLA-B7) or weaker (HLA-B27) graft-versus-host response. ${ }^{74}$

\section{The diagnosis and assessment of aGvHD}

aGvHD typically affects the skin, liver, gastrointestinal tract, and the hematopoietic system ${ }^{75}$ and presents with characteristic rash, abdominal cramps and diarrhea, and deranged liver function tests. Other signs include fever, decrease in performance status, and weight loss. In many cases, the differential is wide, making diagnosis difficult. A biopsy of the skin or gastrointestinal tract can confirm or exclude the diagnosis of aGvHD. When considering liver biopsy in patients with thrombocytopenia, percutaneous transjugular liver biopsy may be safer than percutaneous liver biopsy. ${ }^{76}$

The severity of aGvHD varies from clinically insignificant grades 0 or I disease to clinically significant grades II-IV disease. The first aGvHD classification was published by Glucksberg in 1974. ${ }^{77}$ The Glucksberg classification includes an organ function and performance status assessment and assigns each organ a stage from 0 to 4 (Table 3 ). The organ stages are combined to give the overall grade of aGvHD (Table 4).

There are limitations to the Glucksberg system, and a modified grading system was proposed at a consensus workshop in 1994, which retained the objective Glucksberg organstaging criteria but excluded the subjective performance status criteria (Table 5). ${ }^{78}$ A revised system has subsequently been developed by the International Bone Marrow Transplant Registry (Table 6). ${ }^{79}$

\section{Prevention and treatment}

aGvHD is the major cause of early transplant-related mortality caused by the GvHD itself and treatment-related complications, such as profound immune deficiency and opportunistic infections. To date, it has not been possible to prevent GvHD and maintain the beneficial GvT effect. The primary response to treatment is the most important predictor of long-term survival, as second-line treatments are ineffective.

The two major approaches to the prophylaxis of GvHD following $\mathrm{BM}$ transplantation are pharmacological therapy 
Table 3 The organ grading system for the Glucksberg acute graft-versus-host disease classification

\begin{tabular}{llll}
\hline Stage & Skin/maculopapular rash & $\begin{array}{l}\text { Liver/bilirubin, } \\
\mu \text { mol/L }\end{array}$ & Gastrointestine/diarrhea \\
\hline+ & $<25 \%$ of body surface & $34-50$ & $>500 \mathrm{~mL}$ \\
++ & $25 \%-50 \%$ of body surface & $51-102$ & $>100 \mathrm{~mL}$ \\
+++ & Generalized erythroderma & $103-255$ & $>1500 \mathrm{~mL}$ \\
+++ & Generalized erythroderma with & $>255$ & Severe abdominal pain with \\
& bullae formation and desquamation & & or without ileus \\
\hline
\end{tabular}

and T-cell depletion. The standard drug therapy is a combination treatment with a calcineurin inhibitor (cyclosporine [CsA] or tacrolimus) and "short course" methotrexate (MTX). This regimen is active and gives a reasonable balance between the GvHD and the GvT effect in matched sibling transplants after ablative conditioning regimen. ${ }^{80}$

Primary treatment of aGvHD consists of methylprednisolone and a calcineurin inhibitor for 7-14 days, which is slowly tapered after a complete response to therapy and occurs in $25 \%-40 \%$ of patients with grade II-IV aGvHD. Second-line treatments include high-dose methylprednisolone, tacrolimus, and mycophenolate mofetil, antithymocyte globulin, monoclonal antibodies, such as anti-interleukin-2 (anti-IL-2) receptor antibody, antitumor necrosis factor $\alpha$ (anti-TNF- $\alpha$ ) antibody, and anti-CD52 antibody, pentostatin, and extracorporeal photopheresis. ${ }^{81}$ There are no criteria for identifying patients who are likely to respond to second-line treatment. ${ }^{80,82}$

\section{Chronic GvHD}

cGvHD occurs in around $50 \%$ of long-term survivors of HLA-identical sibling transplants ${ }^{83}$ and is the primary cause of late morbidity and NRM in transplant survivors. The clinical findings may overlap with aGvHD, as both disorders affect similar organs. cGvHD has other features that resemble autoimmune disorders, such as systemic lupus erythematosus, scleroderma, sicca syndrome, eosinophilic

Table 4 The overall Glucksberg grading system for acute GvHD

\begin{tabular}{ll}
\hline Grade of aGvHD & Degree of organ involvement \\
\hline I & Skin + to ++ \\
& Skin + to +++ \\
& Gut and/or liver + \\
& Mild decrease in clinical performance \\
III & Skin ++ to +++ \\
& Gut and/or liver ++ to +++ \\
& Marked decrease in clinical performance \\
IV & Skin ++ to ++++ \\
& Gut and/or liver ++ to ++++ \\
& Extreme decrease in clinical performance
\end{tabular}

Abbreviations: GvHD, graft-versus-host disease, aGvHD, acute GvHD. fasciitis, rheumatoid arthritis, primary biliary sclerosis, bronchiolitis obliterans, and immune cytopenias. ${ }^{83-85}$

Major risk factors for the development of cGvHD include prior aGvHD, a higher degree of HLA mismatch, older age of donor or host, subacute GvHD on skin biopsy, or buccal mucosal biopsy, CMV seropositivity (donor and recipient), and total body irradiation-containing regimens. ${ }^{83,84,86,87}$ Predictive factors include second BM infusions, preceding herpes virus infection, type of underlying malignancy, female donor to male recipient, and no previous blood transfusions before transplantation. ${ }^{83}$

\section{Diagnosis of cGvHD}

cGvHD presents with skin and gastrointestinal involvement and an increasing serum bilirubin concentration. Since the clinical diagnosis is one of exclusion, histological confirmation is often necessary to corroborate a clinical impression of possible cGvHD.

\section{$\mathrm{NIH}$ consensus criteria}

A NIH consensus development project has devised cGvHD diagnostic criteria for use in clinical trials ${ }^{71}$ :

- The broad categories of cGvHD include (1) classic cGvHD (without features or characteristics of aGvHD) and (2) an overlap syndrome in which diagnostic or distinctive features of aGvHD and cGvHD appear together.

- Differential diagnoses must be excluded.

- No time limit is set for the diagnosis of cGvHD.

- At least one diagnostic clinical sign of cGvHD (eg, poikiloderma, esophageal web) must be present or one distinctive manifestation (eg, keratoconjunctivitis sicca) that should be confirmed by biopsy or other relevant tests (eg, Schirmer test).

Table 5 The 1994 Consensus Conference classification of acute graft-versus-host disease

\begin{tabular}{llll}
\hline Grade & Skin & Liver & Gut \\
\hline I & Stage I-2 & Stage 0 & Stage 0 \\
II & Stage 3 or & Stage I or & Stage I \\
III & - & Stage 2-3 or & Stage 2-4 \\
IV & Stage 4 or & Stage 4 & - \\
\hline
\end{tabular}


Table 6 The criteria for the International Bone Marrow Transplant Registry acute graft-versus-host disease staging system

\begin{tabular}{|c|c|c|c|c|c|c|}
\hline \multirow[t]{2}{*}{ Index } & \multicolumn{2}{|l|}{ Skin } & \multicolumn{2}{|l|}{ Liver } & \multicolumn{2}{|c|}{ Gastrointestine } \\
\hline & $\begin{array}{l}\text { Stage } \\
(\max )\end{array}$ & $\begin{array}{l}\text { Extent } \\
\text { of rash }\end{array}$ & $\begin{array}{l}\text { Stage } \\
(\max )\end{array}$ & $\begin{array}{l}\text { Bilirubin, } \\
\mu \mathrm{mol} / \mathrm{L}\end{array}$ & $\begin{array}{l}\text { Stage } \\
(\max )\end{array}$ & $\begin{array}{l}\text { Diarrhea, } \\
\mathrm{mL} / \mathrm{d}\end{array}$ \\
\hline$A$ & 1 & $<25 \%$ & 0 & $<34$ & 0 & $<500$ \\
\hline B & 2 & $25 \%-50 \%$ or & $\mathrm{I}-2$ & $34-102$ & $\mathrm{I}-2$ & $550-1000$ \\
\hline C & 3 & $>50 \%$ or & 3 & $103-225$ & 3 & $>1500$ \\
\hline$D$ & 4 & Bullae or & 4 & $>255$ or & 4 & Pain, ileus \\
\hline
\end{tabular}

\section{Treatment of cGvHD}

A combination of CsA and prednisolone has been the standard first-line therapy for $\mathrm{cGvHD}$ for almost 20 years ${ }^{88}$ There is no standard treatment for $\mathrm{cGvHD}$ that recurs or fails to respond to initial therapy. Experimental therapies include psoralen and ultraviolet light, mycophenolate mofetil, thalidomide, plaquenil, pentostatin, extracorporeal photochemotherapy, ${ }^{89}$ and rituximab. ${ }^{90}$

\section{Morbidity and mortality rates}

Transplantation mortality and morbidity rates have decreased considerably because of improved conditioning regimens, HLA typing, supportive care, and prevention and treatment of serious infections. Overall and event-free survival rates depend on disease stage and pathology. Patients undergoing HLA-matched sibling allogeneic transplantation have the best 5 -year survival rates. ${ }^{91}$ These data should be interpreted with caution, as collection methods, survival quantification, and length of follow-up vary between studies. ${ }^{92}$

Despite the early morbidity associated with HSCT, most of the transplant survivors attain high levels of physical and psychological quality of life (QoL). More than $90 \%$ of patients return to full-time employment within 3-5 years of transplantation. ${ }^{93-95}$ Disease-free patients have a 10 -fold increased risk of mortality when compared with an agematched general population at 2 years after allogeneic HSCT. Mortality remains high even 15 years after transplantation.

Major causes of death are late recurrence of original malignant disease, cGvHD, late infections without GvHD, secondary malignancies, pulmonary complications, and cardiac complications. Up to $20 \%$ of long-term survivors have functional impairments many years after HSCT. Late complications include treatment regimen toxicities, immune deficiency, autoimmune syndromes, growth impairment in children, cognitive dysfunction, second malignancies, chronic GvHD and problems with psychosocial adjustment. These late effects can negatively affect the performance of daily activities, sense of personal well-being, and interpersonal and family relationships.
QoL refers to every dimension of life except length and includes physical abilities, symptoms, social well-being, psycho-emotional status, and spiritual or existential qualities. Following HSCT, QoL ranges from perfect, with no physical, emotional or social sequelae and a greater appreciation for life, to severely compromised with physical disability, pain, and psychological despair. Although long-term survivors report many specific symptoms and limitations in daily activities, almost all indicate that they would undergo the procedure again given similar circumstances. The major risk factors for poor QoL after HSCT are older age, advanced disease at transplantation, cGvHD, and late side effects. ${ }^{96,97}$ Although cGvHD is a strong predictor of poor QoL, health and functional status improves with resolution of GvHD. ${ }^{98,99}$

Gender-specific differences in QoL have been observed, with females more likely to report impairments in psychological and sexual domains. ${ }^{94}$ Cognitive deficits, particularly involving executive function, memory, and motor skills, have been reported in $30 \%-60 \%$ of HSCT survivors. ${ }^{100}$ The risk of developing neuropsychological sequelae is increased in older transplant patients, total body irradiation-based conditioning regimens, and CsA use. Patients may need annual screening for depression and psychological symptoms and counseling for psychological problems.

Individuals undergoing allogeneic HSCT, even when fully recovered, are never free from hospital attendances. Allogeneic HSCT is a lifelong commitment for the patient, their family, primary care physicians, and transplantation team. Robust systems are required for long-term follow-up of survivors after HSCT.

\section{Conclusion}

There have been substantial advances in understanding HSC biology and in the medical management of patients undergoing HSCT. The advent of cord blood banking will allow increasing numbers of patients to receive unrelated allogeneic transplants and create an invaluable resource for scientific research. The development of RIC regimens is 
encouraging and offers the prospect of remissions for older patients who would previously not have been considered for HSCT. Perhaps the greatest challenge remaining is the maximization of the GvT effect, while minimizing the risk of acute and chronic GvHD. Further basic scientific research will delineate the immunological mechanisms behind GvHD and lead to improved medical therapies.

\section{Disclosure}

The authors have no conflicts of interest to declare.

\section{References}

1. Bryder D, Rossi DJ, Weissman IL. Hematopoietic stem cells: the paradigmatic tissue-specific stem cell. Am J Pathol. 2006;169: 338-346.

2. Shizuru JA, Negrin RS, Weissman IL. Hematopoietic stem and progenitor cells: clinical and preclinical regeneration of the hematolymphoid system. Annu Rev Med. 2005;56:509-538.

3. Ogawa M. Differentiation and proliferation of hematopoietic stem cells. Blood. 1993;81:2844-2853.

4. Alcorn MJ, Holyoake TL, Richmond L, et al. CD34-positive cells isolated from cryopreserved peripheral-blood progenitor cells can be expanded ex vivo and used for transplantation with little or no toxicity. J Clin Oncol. 1996;14:1839-1847.

5. Zandstra PW, Lauffenburger DA, Eaves CJ. A ligand-receptor signaling threshold model of stem cell differentiation control: a biologically conserved mechanism applicable to hematopoiesis. Blood. 2000;96:1215-1222.

6. Podesta M. Transplantation hematopoiesis. Curr Opin Hematol. 2001;8:331-336.

7. Lanzkron SM, Collector MI, Sharkis SJ. Homing of long-term and shortterm engrafting cells in vivo. Ann N Y Acad Sci. 1999;872: 48-54.

8. Aiuti A, Webb IJ, Bleul C, Springer T, Gutierrez-Ramos JC. The chemokine SDF-1 is a chemoattractant for human CD34+ hematopoietic progenitor cells and provides a new mechanism to explain the mobilization of $\mathrm{CD}_{3} 4^{+}$progenitors to peripheral blood. J Exp Med. 1997; 185:111-120.

9. Aiuti A, Tavian M, Cipponi A, et al. Expression of CXCR4, the receptor for stromal cell-derived factor-1 on fetal and adult human lymphohematopoietic progenitors. Eur J Immunol. 1999;29:1823-1831.

10. Peled A, Kollet O, Ponomaryov T, et al. The chemokine SDF-1 activates the integrins LFA-1, VLA-4, and VLA-5 on immature human CD34+ cells: role in transendothelial/stromal migration and engraftment of NOD/SCID mice. Blood. 2000;95:3289-3296.

11. Kollet O, Spiegel A, Peled A, et al. Rapid and efficient homing of human $\mathrm{CD} 34^{+} \mathrm{CD} 38\left(-/\right.$ low) $\mathrm{CXCR} 4{ }^{+}$stem and progenitor cells to the bone marrow and spleen of NOD/SCID and NOD/SCID/B2m(null) mice. Blood. 2001;97:3283-3291.

12. Lanzkron SM, Collector MI, Sharkis SJ. Hematopoietic stem cell tracking in vivo: a comparison of short-term and long-term repopulating cells. Blood. 1999;93:1916-1921.

13. Mahmud N, Devine SM, Weller KP, et al. The relative quiescence of hematopoietic stem cells in nonhuman primates. Blood. 2001;97: 3061-3068.

14. Burt RK, Traynor A, Burns W. Hematopoietic stem cell transplantation of multiple sclerosis, rheumatoid arthritis, and systemic lupus erythematosus. Cancer Treat Res. 1999;101:157-184.

15. Bonini C, Ferrari G, Verzeletti S, et al. HSV-TK gene transfer into donor lymphocytes for control of allogeneic graft-versus-leukemia. Science. 1997;276:1719-1724.

16. Cohen JL, Boyer O, Salomon B, et al. Prevention of graft-versus-host disease in mice using a suicide gene expressed in T lymphocytes. Blood. 1997;89:4636-4645.
17. Gandy KL, Weissman IL. Tolerance of allogeneic heart grafts in mice simultaneously reconstituted with purified allogeneic hematopoietic stem cells. Transplantation. 1998;65:295-304.

18. Quesenberry PJ, Dooner G, Colvin G, Abedi M. Stem cell biology and the plasticity polemic. Exp Hematol. 2005;33:389-394.

19. Abrahamsen IW, Somme S, Heldal D, Egeland T, Kvale D, Tjonnfjord GE. Immune reconstitution after allogeneic stem cell transplantation: the impact of stem cell source and graft-versus-host disease. Haematologica. 2005;90:86-93.

20. Kolb HJ, Mittermuller J, Clemm C, et al. Donor leukocyte transfusions for treatment of recurrent chronic myelogenous leukemia in marrow transplant patients. Blood. 1990;76:2462-2465.

21. Anasetti C, Hansen JA. Effect of HLA incompatibility in marrow transplantation from unrelated and HLA-mismatched related donors. Transfus Sci. 1994;15:221-230.

22. Anasetti C, Petersdorf EW, Martin PJ, Woolfrey A, Hansen JA. Trends in transplantation of hematopoietic stem cells from unrelated donors. Curr Opin Hematol. 2001;8:337-341.

23. Gluckman E, Broxmeyer HA, Auerbach AD, et al. Hematopoietic reconstitution in a patient with Fanconi's anemia by means of umbilicalcord blood from an HLA-identical sibling. N Engl J Med. 1989;321: $1174-1178$.

24. Kurtzberg J, Laughlin M, Graham ML, et al. Placental blood as a source of hematopoietic stem cells for transplantation into unrelated recipients. N Engl J Med. 1996;335:157-166.

25. Wagner JE, Kernan NA, Steinbuch M, Broxmeyer HE, Gluckman E. Allogeneic sibling umbilical-cord-blood transplantation in children with malignant and non-malignant disease. Lancet. 1995;346:214-219.

26. Fischer A, Landais P, Friedrich W, et al. European experience of bonemarrow transplantation for severe combined immunodeficiency. Lancet. 1990;336:850-854.

27. Lucarelli G, Galimberti M, Polchi P, et al. Bone marrow transplantation in patients with thalassemia. $N$ Engl J Med. 1990;322:417-421.

28. Bahceci E, Read EJ, Leitman S, et al. CD34+ cell dose predicts relapse and survival after T-cell-depleted HLA-identical haematopoietic stem cell transplantation (HSCT) for haematological malignancies. $\mathrm{Br} J$ Haematol. 2000;108:408-414.

29. Braine HG, Sensenbrenner LL, Wright SK, Tutschka PJ, Saral R, Santos GW. Bone marrow transplantation with major ABO blood group incompatibility using erythrocyte depletion of marrow prior to infusion. Blood. 1982;60:420-425.

30. Buckner CD, Petersen FB, Bolonesi BA. Bone marrow donors. In: Forman SJ, Blume KG, Thomas ED, editors. Bone Marrow Transplantation. Boston, MA: Blackwell Scientific Publications; 1994: 259-270.

31. Bortin MM, Buckner CD. Major complications of marrow harvesting for transplantation. Exp Hematol. 1983;11:916-921.

32. Bensinger W, Singer J, Appelbaum F, et al. Autologous transplantation with peripheral blood mononuclear cells collected after administration of recombinant granulocyte stimulating factor. Blood. 1993;81:3158-3163.

33. Sheridan WP, Begley CG, Juttner CA, et al. Effect of peripheral-blood progenitor cells mobilised by filgrastim (G-CSF) on platelet recovery after high-dose chemotherapy. Lancet. 1992;339:640-644.

34. Hartmann O, Le Corroller AG, Blaise D, et al. Peripheral blood stem cell and bone marrow transplantation for solid tumors and lymphomas: hematologic recovery and costs. A randomized, controlled trial. Ann Intern Med. 1997;126:600-607.

35. Vellenga E, van AM, Croockewit AJ, et al. Autologous peripheral blood stem cell transplantation in patients with relapsed lymphoma results in accelerated haematopoietic reconstitution, improved quality of life and cost reduction compared with bone marrow transplantation: The Hovon 22 Study. Br J Haematol. 2001;114:319-326.

36. Weaver $\mathrm{CH}$, Hazelton B, Birch R, et al. An analysis of engraftment kinetics as a function of the $\mathrm{CD} 34$ content of peripheral blood progenitor cell collections in 692 patients after the administration of myeloablative chemotherapy. Blood. 1995;86:3961-3969. 
37. Bensinger WI, Weaver CH, Appelbaum FR, et al. Transplantation of allogeneic peripheral blood stem cells mobilized by recombinant human granulocyte colony-stimulating factor. Blood. 1995;85:1655-1658.

38. Korbling M, Przepiorka D, Huh YO, et al. Allogeneic blood stem cell transplantation for refractory leukemia and lymphoma: potential advantage of blood over marrow allografts. Blood. 1995;85:1659-1665.

39. Schmitz N, Dreger P, Suttorp M, et al. Primary transplantation of allogeneic peripheral blood progenitor cells mobilized by filgrastim (granulocyte colony-stimulating factor). Blood. 1995;85:1666-1672.

40. Cesaro S, Marson P, Gazzola MV, et al. The use of cytokine-stimulated healthy donors in allogeneic stem cell transplantation. Haematologica. 2002;87:35-41.

41. Brown SL, Dale DC. Spontaneous splenic rupture following administration of granulocyte colony-stimulating factor (G-CSF): occurrence in an allogeneic donor of peripheral blood stem cells. Biol Blood Marrow Transplant. 1997;3:341-343.

42. Hatzimichael E, Benetatos L, Stebbing J, Kapsali E, Panayiotopoulou S, Bourantas KL. Spontaneous splenic haematoma in a multiple myeloma patient receiving pegfilgrastim support. Clin Lab Haematol. 2006;28:416-418

43. Masood N, Shaikh AJ, Memon WA, Idress R. Splenic rupture, secondary to G-CSF use for chemotherapy induced neutropenia: a case report and review of literature. Cases J. 2008;1:418.

44. Nuamah NM, Goker H, Kilic YA, Dagmoura H, Cakmak A. Spontaneous splenic rupture in a healthy allogeneic donor of peripheral-blood stem cell following the administration of granulocyte colony-stimulating factor (g-csf). A case report and review of the literature. Haematologica. 2006;91:ECR08.

45. Flowers ME, Parker PM, Johnston LJ, et al. Comparison of chronic graft-versus-host disease after transplantation of peripheral blood stem cells versus bone marrow in allogeneic recipients: long-term follow-up of a randomized trial. Blood. 2002;100:415-419.

46. Mohty M, Kuentz M, Michallet M, et al. Chronic graft-versus-host disease after allogeneic blood stem cell transplantation: long-term results of a randomized study. Blood. 2002;100:3128-3134.

47. Bradley MB, Cairo MS. Cord blood immunology and stem cell transplantation. Hum Immunol. 2005;66:431-446.

48. Wang JC, Doedens M, Dick JE. Primitive human hematopoietic cells are enriched in cord blood compared with adult bone marrow or mobilized peripheral blood as measured by the quantitative in vivo SCID-repopulating cell assay. Blood. 1997;89:3919-3924.

49. Hogan CJ, Shpall EJ, McNulty O, et al. Engraftment and development of human $\mathrm{CD}^{+} 4^{+}$-enriched cells from umbilical cord blood in NOD/LtSz-scid/scid mice. Blood. 1997;90:85-96.

50. Grewal SS, Barker JN, Davies SM, Wagner JE. Unrelated donor hematopoietic cell transplantation: marrow or umbilical cord blood? Blood. 2003;101:4233-4244.

51. Delaney C, Heimfeld S, Brashem-Stein C, Voorhies H, Manger RL, Bernstein ID. Notch-mediated expansion of human cord blood progenitor cells capable of rapid myeloid reconstitution. Nat Med. 2010;16: 232-236.

52. Wang J, Zhan P, Ouyang J, Chen B, Zhou R, Yang Y. Unrelated donor umbilical cord blood transplantation versus unrelated donor bone marrow transplantation in adult and pediatric patients: a meta-analysis. Leuk Res. 2010;34(8):1018-1022.

53. Gribben JG, Zahrieh D, Stephans K, et al. Autologous and allogeneic stem cell transplantations for poor-risk chronic lymphocytic leukemia. Blood. 2005;106:4389-4396.

54. Michallet M, Archimbaud E, Bandini G, et al; European Group for Blood and Marrow Transplantation and the International Bone Marrow Transplant Registry. HLA-identical sibling bone marrow transplantation in younger patients with chronic lymphocytic leukemia. Ann Intern Med. 1996;124:311-315.

55. Lim Z, Brand R, Martino R, et al. Allogeneic hematopoietic stem-cell transplantation for patients 50 years or older with myelodysplastic syndromes or secondary acute myeloid leukemia. J Clin Oncol. 2010;28:405-411.
56. Hsieh MY, Chiou TJ, Hung GY, Yen HJ. Outcomes of matched sibling and alternative donor stem cell transplantation for 26 children with severe aplastic anemia. Int J Hematol. 2010;91:54-60.

57. Sorror ML, Maris MB, Storb R, et al. Hematopoietic cell transplantation (HCT)-specific comorbidity index: a new tool for risk assessment before allogeneic HCT. Blood. 2005;106:2912-2919.

58. Sorror ML, Storer BE, Maloney DG, Sandmaier BM, Martin PJ, Storb R. Outcomes after allogeneic hematopoietic cell transplantation with nonmyeloablative or myeloablative conditioning regimens for treatment of lymphoma and chronic lymphocytic leukemia. Blood. 2008; 111:446-452.

59. Farina L, Bruno B, Patriarca F, et al. The hematopoietic cell transplantation comorbidity index (HCT-CI) predicts clinical outcomes in lymphoma and myeloma patients after reduced-intensity or non-myeloablative allogeneic stem cell transplantation. Leukemia. 2009;23:1131-1138.

60. Majhail NS, Brunstein CG, McAvoy S, et al. Does the hematopoietic cell transplantation specific comorbidity index predict transplant outcomes? A validation study in a large cohort of umbilical cord blood and matched related donor transplants. Biol Blood Marrow Transplant. 2008:14:985-992.

61. Afessa B, Peters SG. Major complications following hematopoietic stem cell transplantation. Semin Respir Crit Care Med. 2006;27:297-309.

62. Marr KA. Antifungal prophylaxis in hematopoietic stem cell transplant recipients. Curr Opin Infect Dis. 2001;14:423-426.

63. Meyers JD. Infection in bone marrow transplant recipients. Am J Med. 1986;81:27-38.

64. Boeckh M, Leisenring W, Riddell SR, et al. Late cytomegalovirus disease and mortality in recipients of allogeneic hematopoietic stem cell transplants: importance of viral load and T-cell immunity. Blood. 2003;101:407-414.

65. Andrei G, De CE, Snoeck R. Novel inhibitors of human CMV. Curr Opin Investig Drugs. 2008;9:132-145.

66. Li CR, Greenberg PD, Gilbert MJ, Goodrich JM, Riddell SR. Recovery of HLA-restricted cytomegalovirus (CMV)-specific T-cell responses after allogeneic bone marrow transplant: correlation with CMV disease and effect of ganciclovir prophylaxis. Blood. 1994;83:1971-1979.

67. Schmidt-Hieber M, Schwarck S, Stroux A, et al. Prophylactic iv Igs in patients with a high risk for CMV after allo-SCT. Bone Marrow Transplant. 2009;44:185-192.

68. Tuthill M, Chen F, Paston S, de La Pena H, Rusakiewicz S, Madrigal A. The prevention and treatment of cytomegalovirus infection in haematopoietic stem cell transplantation. Cancer Immunol Immunother. 2009;58:1481-1488.

69. Paston SJ, Dodi IA, Madrigal JA. Progress made towards the development of a CMV peptide vaccine. Hum Immunol. 2004;65:544-549.

70. Pass RF, Zhang C, Evans A, et al. Vaccine prevention of maternal cytomegalovirus infection. $N$ Engl J Med. 2009;360:1191-1199.

71. Filipovich AH, Weisdorf D, Pavletic S, et al. National Institutes of Health consensus development project on criteria for clinical trials in chronic graft-versus-host disease: I. Diagnosis and staging working group report. Biol Blood Marrow Transplant. 2005;11:945-956.

72. Gale RP, Bortin MM, van Bekkum DW, et al. Risk factors for acute graft-versus-host disease. Br J Haematol. 1987;67:397-406.

73. Hahn T, McCarthy PL Jr, Zhang MJ, et al. Risk factors for acute graftversus-host disease after human leukocyte antigen-identical sibling transplants for adults with leukemia. J Clin Oncol. 2008;26:5728-5734.

74. Remberger M, Persson U, Hauzenberger D, Ringden O. An association between human leucocyte antigen alleles and acute and chronic graft-versus-host disease after allogeneic haematopoietic stem cell transplantation. Br J Haematol. 2002;119:751-759.

75. Couriel D, Caldera H, Champlin R, Komanduri K. Acute graftversus-host disease: pathophysiology, clinical manifestations, and management. Cancer. 2004;101:1936-1946.

76. Firoz BF, Lee SJ, Nghiem P, Qureshi AA. Role of skin biopsy to confirm suspected acute graft-vs-host disease: results of decision analysis. Arch Dermatol. 2006;142:175-182. 
77. Glucksberg H, Storb R, Fefer A, et al. Clinical manifestations of graft-versus-host disease in human recipients of marrow from HL-A-matched sibling donors. Transplantation. 1974;18:295-304.

78. Przepiorka D, Weisdorf D, Martin P, et al. 1994 Consensus Conference on Acute GvHD Grading. Bone Marrow Transplant. 1995;15: 825-828.

79. Rowlings PA, Przepiorka D, Klein JP, et al. IBMTR Severity Index for grading acute graft-versus-host disease: retrospective comparison with Glucksberg grade. Br J Haematol. 1997;97:855-864.

80. Storb R, Deeg HJ, Whitehead J, et al. Methotrexate and cyclosporine compared with cyclosporine alone for prophylaxis of acute graft versus host disease after marrow transplantation for leukemia. $N$ Engl J Med. 1986;314:729-735.

81. Greinix HT, Knobler RM, Worel N, et al. The effect of intensified extracorporeal photochemotherapy on long-term survival in patients with severe acute graft-versus-host disease. Haematologica. 2006;91: 405-408

82. Kim SS. Treatment options in steroid-refractory acute graft-versus-host disease following hematopoietic stem cell transplantation. Ann Pharmacother. 2007;41:1436-1444.

83. Carlens S, Ringden O, Remberger M, et al. Risk factors for chronic graftversus-host disease after bone marrow transplantation: a retrospective single centre analysis. Bone Marrow Transplant. 1998;22:755-761.

84. Sullivan KM, Shulman HM, Storb R, et al. Chronic graft-versus-host disease in 52 patients: adverse natural course and successful treatment with combination immunosuppression. Blood. 1981;57:267-276.

85. Sullivan KM. Acute and chronic graft-versus-host disease in man. Int J Cell Cloning. 1986;4(Suppl 1):S42-S93.

86. Higman MA, Vogelsang GB. Chronic graft versus host disease. $\mathrm{Br} J$ Haematol. 2004;125:435-454.

87. Storb R, Prentice RL, Sullivan KM, et al. Predictive factors in chronic graft-versus-host disease in patients with aplastic anemia treated by marrow transplantation from HLA-identical siblings. Ann Intern Med. 1983;98:461-466.

88. Sullivan KM, Witherspoon RP, Storb R, et al. Alternating-day cyclosporine and prednisone for treatment of high-risk chronic graftv-host disease. Blood. 1988;72:555-561.

89. Vogelsang GB. How I treat chronic graft-versus-host disease. Blood. 2001;97:1196-1201

90. Cutler C, Miklos D, Kim HT, et al. Rituximab for steroid-refractory chronic graft-versus-host disease. Blood. 2006;108:756-762.
91. Weisdorf DJ, Nelson G, Lee SJ, et al. Sibling versus unrelated donor allogeneic hematopoietic cell transplantation for chronic myelogenous leukemia: refined HLA matching reveals more graftversus-host disease but not less relapse. Biol Blood Marrow Transplant. 2009; $15: 1475-1478$.

92. Saarinen-Pihkala UM, Gustafsson G, Ringden O, et al. No disadvantage in outcome of using matched unrelated donors as compared with matched sibling donors for bone marrow transplantation in children with acute lymphoblastic leukemia in second remission. J Clin Oncol. 2001;19:3406-3414.

93. Chiodi S, Spinelli S, Ravera G, et al. Quality of life in 244 recipients of allogeneic bone marrow transplantation. Br J Haematol. 2000;110:614-619.

94. Heinonen H, Volin L, Uutela A, Zevon M, Barrick C, Ruutu T. Quality of life and factors related to perceived satisfaction with quality of life after allogeneic bone marrow transplantation. Ann Hematol. 2001;80:137-143.

95. Kiss TL, Abdolell M, Jamal N, Minden MD, Lipton JH, Messner HA. Long-term medical outcomes and quality-of-life assessment of patients with chronic myeloid leukemia followed at least 10 years after allogeneic bone marrow transplantation. J Clin Oncol. 2002;20: 2334-2343.

96. Andrykowski MA, Greiner CB, Altmaier EM, et al. Quality of life following bone marrow transplantation: findings from a multicentre study. Br J Cancer. 1995;71:1322-1329.

97. Baker F, Wingard JR, Curbow B, et al. Quality of life of bone marrow transplant long-term survivors. Bone Marrow Transplant. 1994;13: 589-596.

98. Fraser CJ, Bhatia S, Ness K, et al. Impact of chronic graftversus-host disease on the health status of hematopoietic cell transplantation survivors: a report from the Bone Marrow Transplant Survivor Study. Blood. 2006;108:2867-2873.

99. Lee SJ, Fairclough D, Parsons SK, et al. Recovery after stem-cell transplantation for hematologic diseases. J Clin Oncol. 2001;19 242-252.

100. Harder H, van Gool AR, Cornelissen JJ, et al. Assessment of pre-treatment cognitive performance in adult bone marrow or haematopoietic stem cell transplantation patients: a comparative study. Eur J Cancer. 2005;41:1007-1016.

\section{Publish your work in this journal}

Stem Cells and Cloning: Advances and Applications is an international, peer-reviewed, open access journal. Areas of interest in stem cell research include: Embryonic cell stems; Adult stem cells; Blastocysts; Cordblood stem cells; Stem cell transformation and culture; Therapeutic cloning; Umbilical cord blood and bone marrow cells; Laboratory,

\section{Dovepress}

animal and human therapeutic studies; Philosophical and ethical issues related to stem cell research. This journal is indexed on CAS. The manuscript management system is completely online and includes a quick and fair peer-review system. Visit http://www.dovepress.com/ testimonials.php to read real quotes from published authors 